\title{
Mechanical Analysis and Structure Health Monitoring of Congruence Beam Cable-stayed Bridge
}

\author{
JI De-jun, WANG Ke-jin, WANG Yong-liang \\ (High-Grade Highway Construction Management Department of Qinghai Province, \\ Xining 810000, China)
}

\begin{abstract}
Keywords: Cable-stayed bridge; Finite element method; Structure response; Structure health monitoring

Abstract: The Wajiatan Yellow river bridge is a congruence beam cable-stayed bridge, which was analyzed by finite element method to simulate the structure dynamic characteristics and structure response under different loads. By numerical simulations, the structure dangerous points and structure monitoring priorities can be obtained. The analysis results can be used to guide the arrangement of measurement gauges in bridge health monitoring.
\end{abstract}

\section{Introduction}

There are many factors lead to bridge safety problems. It is necessary to identify the hazard factors to design bridge. During the life cycle of the bridge health monitoring system, the factors lead to threat of structural safety[1 3]. While designing a bridge health monitoring system, the structural analysis should be carried out firstly, and then the arrangement of measurement gauges should be determined. The mechanical behavior of the bridge structure should be grasped, and the key components and positions of the structural stress should be clarified to guide the sensor arrangement[4]. This paper analyzes the static, dynamic and seismic response of the Wajiatan Yellow river bridge to grasp the law of the structure force and examine the key parts of the structure stress, it provides scientifically and reasonably detailed information for arranging measuring points [5].

The Wajiatan Yellow river bridge is the largest cable-stayed bridge with double pylons and double cable planes in Qinghai Province. The main bridge is 1000 meters in length $(104+116+560+116+104)$, which is steel-concrete congruence beam cable-stayed bridge with double pylons and double cable planes. The total height of the main towers are 186.2 and 193.6 meters respectively. The inclined cables are arranged in a fan-shaped arrangement and 88 pairs of cables are made of low-relaxation galvanized high-strength steel wires. The cable stays are anchored on the main girder using an anchor plate. The main beams, crossbeams and small longitudinal beams whose shapes are connected by a friction type high-strength bolt into steel girder sections. The main girder is equipped with a longitudinally movable and a vertically rigid spherical[5].

\section{Analysis of the risk of cable-stayed bridges}

The structural analysis of damage sensitivity and other aspects is carried out. At the same time, combined with the measured data can be further calculated and analyzed for structural state assessment[6 7]. In this paper, the main calculation contents include: stresses of main beam in operation stage, stresses of cable, displacements of tower and beam, etc.

\section{Numerical simulation model}

The stay cable adopts a rod unit, and its elasticity modulus is modified according to the Ernst formula. The main beam and the cable tower adopt linear finite strain beam elements. In the analysis of the self-vibration characteristics of the finished bridge state, the secondary dead load is simulated by the mass unit. The bottom of the cable tower is fixed. The tower girders are all living hinge supports and a single rod unit is used to simulate vertical support. The end of the concrete beam is used as the origin of the coordinate system. The final finite element model is shown in Fig. 1. 

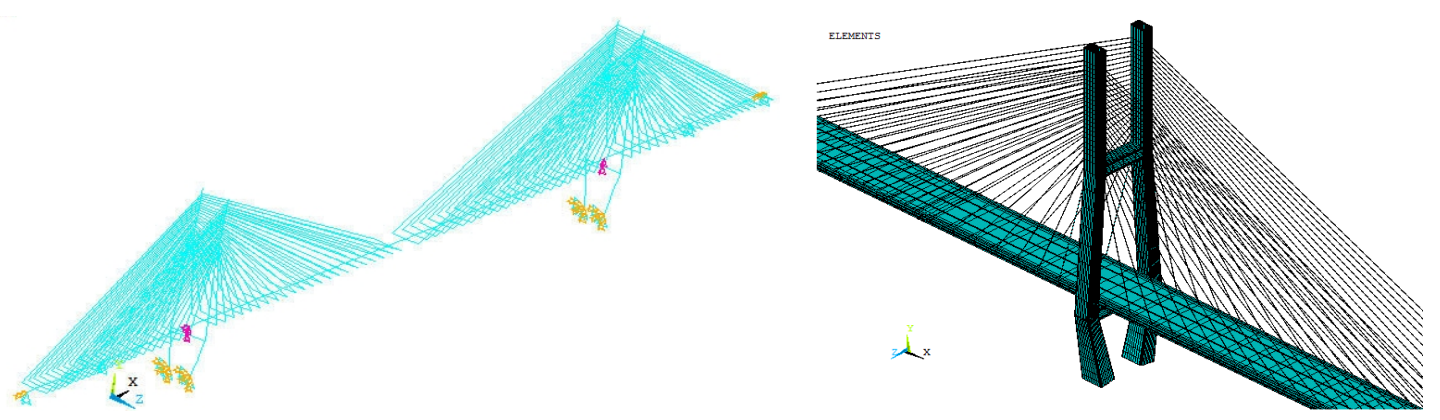

Fig. 1 Finite element model

\section{Static analysis}

Considering the structural response under dead load and live load, the static calculation and analysis of the structure is performed. Under the combined effects of dead load and live load, the stress envelope diagrams for cables and towers are shown in Fig. 2 to Fig.4, respectively. Under the action of live load, the displacement envelope diagrams of beams and towers are shown in Fig. 5 to Fig.7, respectively.

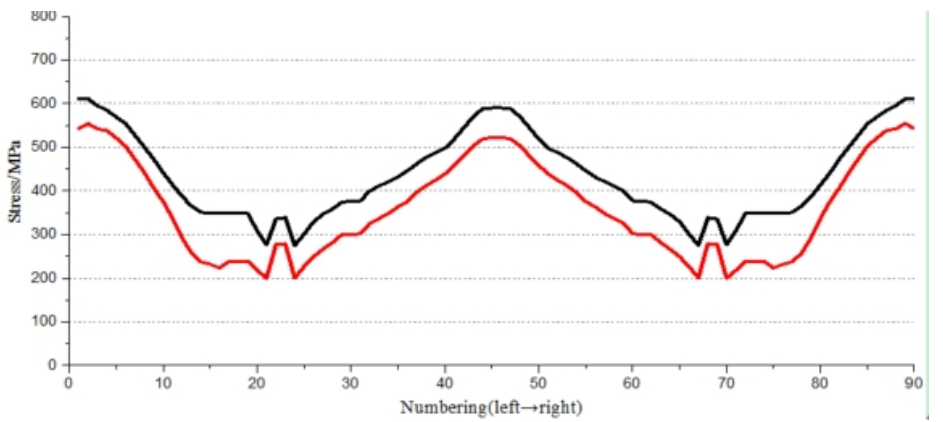

Fig. 2 The stay cable stress envelope

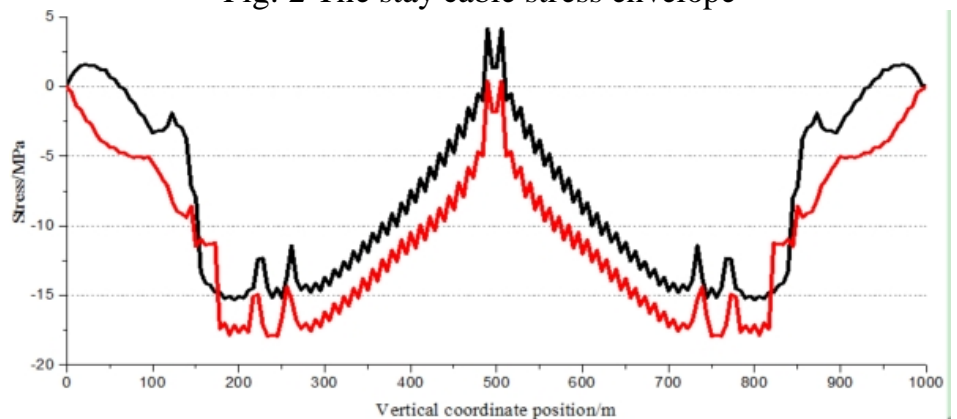

Fig. 3 The stress envelope of upper edge of main girder

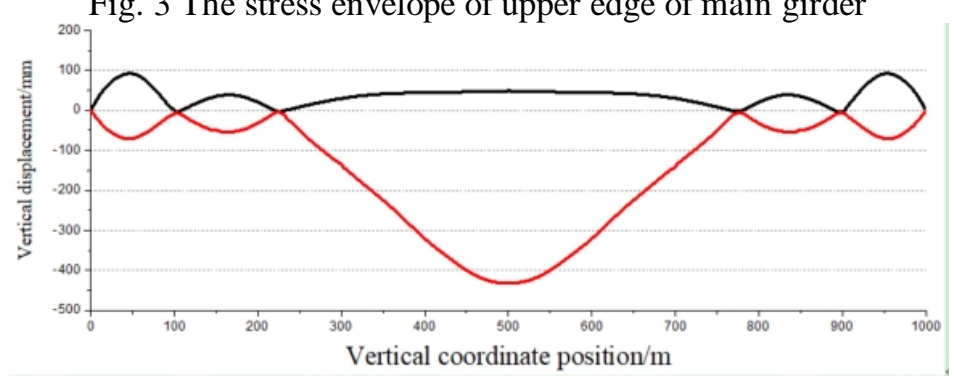

Fig.4The vertical displacement envelope of main girder 

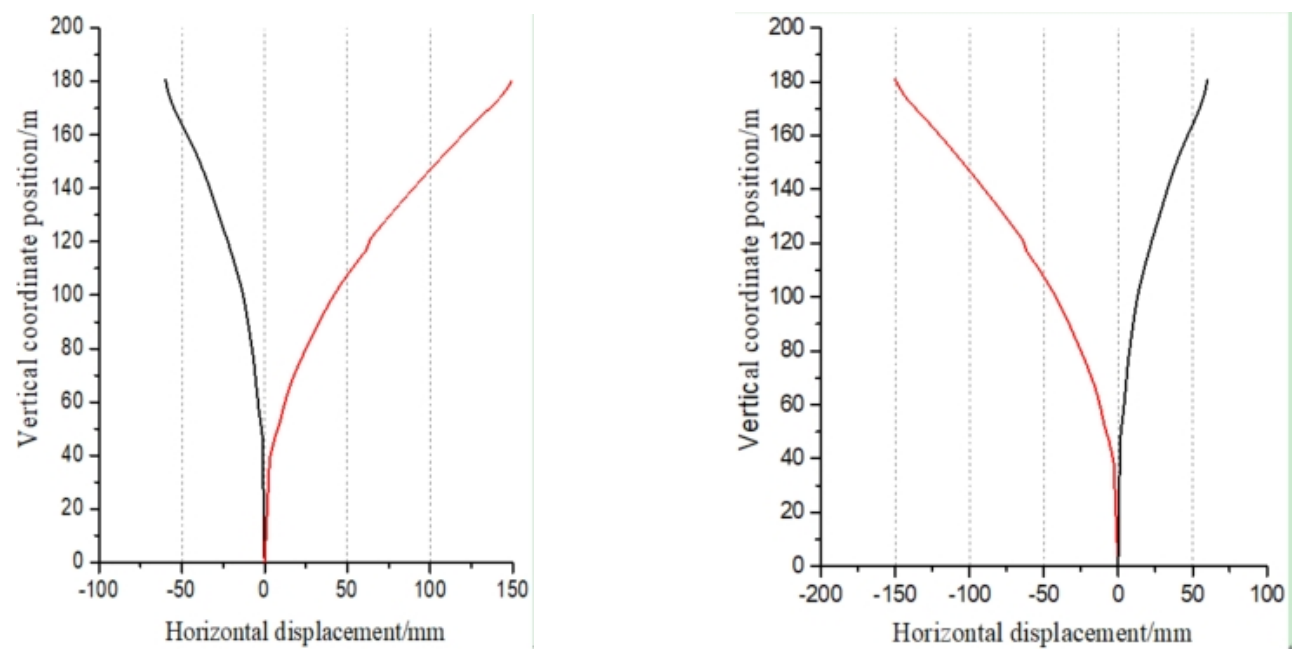

Fig. 5longitudinal displacement envelope of 20\# tower Fig.6ongitudinal displacement envelope of 21\# tower

Through calculation and analysis, the maximum vertical deflection occurs at the mid-span position of the main girder. However, the maximum horizontal displacement of the cable tower occurs at the top. These locations are not only the key points of the structure displacement control, but also the control parameter selection of the monitoring instrument. Under the action of load, the distribution of cable force and stress is more uniform, the tail cable and the shortest cable with higher stress levels and large change amplitudes can be selected by monitoring. The stress of the girder is greater at the cable tower and the mid-span of side span. These locations can be preliminarily identified as the critical control points for structural stress.

\section{Dynamic characteristics analysis}

The bridge dynamic parameters can reflect the overall characteristics of the bridge structure. The important structural self-vibration characteristics are shown in Table 1.

Table 1. Structural self-vibration characteristics and description

\begin{tabular}{|c|c|c|c|}
\hline Order & Frequency $(\mathrm{Hz})$ & Period $(\mathrm{s})$ & Mode description \\
\hline 1 & 0.1132 & 8.8370 & main beams longitudinal drift \\
\hline 2 & 0.2624 & 3.8108 & Main beam first-order symmetrical lateral bending \\
\hline 3 & 0.2766 & 3.6151 & Main beam first-order symmetrical vertical bending \\
\hline 4 & 0.3298 & 3.0319 & Main beam first-order symmetrical twist \\
\hline 5 & 0.3567 & 2.8033 & number 21 tower column side bend \\
\hline 6 & 0.3620 & 2.7622 & Main beam first-order anti-scaling \\
\hline 7 & 0.3824 & 2.6147 & number 20 tower column side bend \\
\hline
\end{tabular}

As shown in dynamic analysis, the first vibration mode of the structure is a longitudinal drift. It is possible to arrange a forward bridge acceleration measurement point. The second-order vibration mode is symmetrical lateral bending, and a lateral acceleration measuring point can be arranged at the maximum lateral vibration amplitude of the main span. A vertical acceleration measuring point is arranged in upstream and downstream of the mid-span.

\section{Seismic response analysis}

While an earthquake occurs, the vibrations reflected on the ground surface may not be exactly the same because the seismic waves received by the ground point may pass through different paths. The two main towers of the Wajiatan Yellow river bridge are far apart, and the seismic waves received by the different source distances are bound to have a phase difference[8 9]. In this paper, the large-mass method is used to analyze the response of the bridge under the excitation of seismic waves, and the influence of the seismic traveling wave effect on the structure is analyzed.

The basic earthquake acceleration in the area is located as $0.1 \mathrm{~g}$ with the fortification intensity VII. Based on the above features, the adjusted EL-Centro wave is used as the input seismic wave in the 
longitudinal direction. The original acceleration peak value of $341.7 \mathrm{gal}$ is adjusted to $100 \mathrm{gal}$. The pile foundation of the bridge is located directly on the bedrock. The seismic wave velocity is $2000 \mathrm{~m} / \mathrm{s}$, and the span between the two main towers of the bridge is $560 \mathrm{~m}$. Considering the non-uniform excitation of the traveling wave effect, the longitudinal seismic action is used to calculate the structural response of the traveling wave effect. Compared with the uniform excitation conditions, the mid-span vertical displacement of the main beam and the longitudinal displacement of the top of tower are shown in Fig. 8 to Fig. 9 respectively.
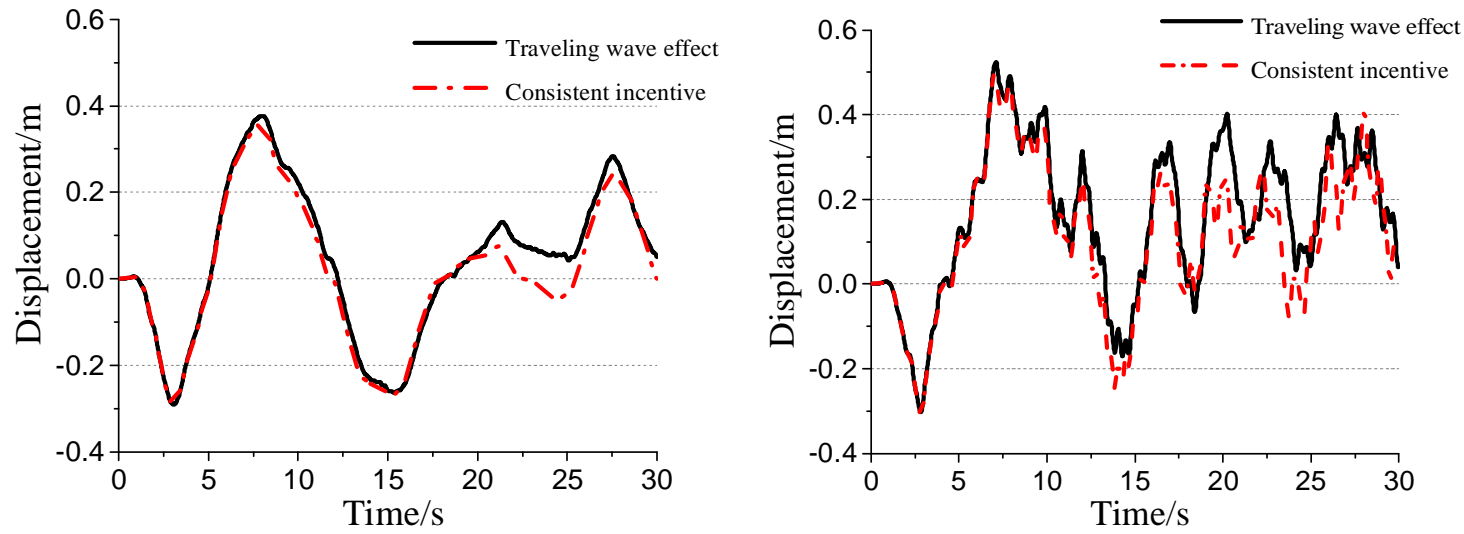

Fig. 7 he mid-span vertical displacement Fig. 8number 21 tower top longitudinal displacement

Considering the traveling wave effect for seismic response calculation, the peak value of longitudinal displacement at the top of number 20 tower is $43.4 \mathrm{~cm}$. The mid-span vertical displacement of the main beam is $37.7 \mathrm{~cm}$ and the peak value of longitudinal displacement at the top of number 21 tower is $49.4 \mathrm{~cm}$. With unanimous excitation, the peak displacement of the top of number 20 tower is $41.1 \mathrm{~cm}$. The mid-span vertical displacement of the main beam is $35.8 \mathrm{~cm}$ and the peak displacement at the top of tower number 21 is $52.4 \mathrm{~cm}$. Comparing the results of the analysis, the time-history response of the structure under the consistent ground excitation are less different. The seismic traveling wave effect of this bridge is not obvious, therefore, only one location can be considered for the seismic survey point of the bridge monitoring system.

\section{Conclusions}

In order to assessment the state and safety of the bridge structure, the measurement points of the structural health monitoring system are arranged on the key points. It is necessary to consider the contradiction between the quantity of measuring points and the cost of instrument and equipment. In this case, it is necessary to carry out static and dynamic analysis of the structure. In the paper, by numerical analysis of structural multi-response calculations, the conclusions are drawn as follow:

(1) Mid-span of main span and the top of the main tower are key points of structural displacement control, which are also determine the choice of monitoring instrument parameters.

(2) Cable force monitoring can be chosen to monitor the longest and shortest cable. The main beam stress monitoring section can be selected at the cable tower and at the mid-span of side span.

(3) Acceleration measurement points of the dynamic characteristics can be arranged at the maximum amplitude of the vibration mode according to the selected order. With the effect of earthquake, the traveling wave effect of the bridge is not obvious.

\section{References}

[1]. Wu X, Wang Y Q, Qu Z L. Reinforcement scheme of cable safety performance for large-span cable-stayed bridge[J]. Journal of Shenyang Institute of Engineering, 2010,32(1):110-114.

[2]. Xiong T. Vulnerability analysis of concrete cable-stayed bridges[D]. Chengdu: Southwest Jiaotong University, 2009. 
[3]. Huang C, Zhao L, Bu Y Z. Sensitivity Analysis of Single-parameters for Super-span Cable-stayed Bridge Based on Geometry Control Method[J]. Journal of Highway and Transportation Research and Development, 2012,29(5):70-75.

[4]. Jiang X L, Cheng G. Optimal sensor placement for bridge modal testing based on EfI method[J]. Bridge Construction, 2012,42 (2):59-65.

[5]. Li A Q, Liao C Q. Health monitoring of bridge structure[M]. Beijing: China Communication Press, 2009.

[6]. Zong Z H, Ren W X. Finite element model updating and model validation of bridge structure[M]. Beijing: China Communication Press,2012.

[7]. Lin J H, Zhang Y H, Zhao Y. Seismic analysis methods of long-span structures and recent advances[J]. Advances in Mechanics, 2001,31(3):350-360.

[8]. Wan S M. Analysis on dynamic characteristic and seismic responses of alond-span multi-tower cable stayed bridge[D]. Chengdu: Southwest Jiaotong University, 2009. 